\title{
FAKTOR YANG MEMPENGARUHI IMPULSE BUYING KONSUMEN SAAT MOMENT HARI BELANJA ONLINE NASIONAL (HARBOLNAS)
}

\author{
Yenny Yuniarti' ${ }^{1)}$, Maulidia Imastary Tan ${ }^{2)}$, Ade Perdana Siregar ${ }^{3)}$, \\ Adi Ikhsan Syukri Amri ${ }^{4)}$ \\ 1,2,3,4) Dosen Jurusan Manajemen FEB Universitas Jambi \\ Email : yenny_yuniarti@unja.ac.id
}

\begin{abstract}
Abstrak
Hari Belanja Online Nasional (Harbolnas) merupakan suatu perayaan yang diciptakan idEA (Asosiasi E-commerce Indonesia) guna mendorong dan mengedukasi masyarakat Indonesia mengenai kemudahan berbelanja secara online. Menurut Menteri Komunikasi dan Informatika, pada tahun 2018 sebanyak 6,5 juta pelaku usaha mikro, kecil dan menengah (UMKM) yang terlibat dalam kegiatan harbolnas. E-commerce sendiri menimbulkan perubahan perilaku pembelian konsumen menjadi impulse buying, yaitu melakukan pembelian yang tidak direncanakan (Natasya, 2016). Metode penarikan sampel purposive sampling yaitu konsumen yang pernah melakukan transaksi saat harbolnas. Metode analisis yang digunakan deskriptif kualitatif dengan alat analisis Cross Tabulation. Temuan dalam penelitian ini yaitu faktor yang paling mempengaruhi impulse buying konsumen online store saat moment harbolnas adalah emosi, yaitu keinginan untuk menunjukan jati diri.
\end{abstract}

Kata Kunci : e-commerce, impulse buying, HARBOLNAS

\begin{abstract}
Hari belanja online nasional (Harbolnas) is a celebration created by idEA (Indonesian Ecommerce Association) to encourage and educate the Indonesian people about the convenience of shopping online. According to the Minister of Communication andInformation, in 2018 there were 6.5 million micro, small and medium enterprises (MSMEs) involved in harbolnas activities. E-commerce itself causes changes in consumer buying behavior into impulse buying, which is making unplanned purchases (Natasya, 2016). Purposive sampling method is a method for consumers who have made transactions during Harbolnas. The analytical method used is descriptive qualitative. The findings in this study are the factors that most influence the impulse buying of online store consumers during Harbolnas moment are emotions, namely the desire to show identity.
\end{abstract}

Keyword : e-commerce, impulse buying, Harbolnas.

\section{PENDAHULUAN}

Hari Belanja Online Nasional ( Harbolnas ) merupakan suatu perayaan yang diciptakan idEA (Asosiasi E-commerce Indonesia) guna mendorong dan mengedukasi masyarakat Indonesia mengenai kemudahan berbelanja secara online kapan saja dan di mana saja selama 24 jam. Menurut Menteri Komunikasi dan Informatika, pada tahun 2018 sebanyak 6,5 juta pelaku usaha mikro, kecil dan menengah (UMKM) yang terlibat dalam kegiatan harbolnas. Menurut data McKinsey, sepanjang tahun 2017 pertumbuhan ecommerce di Indonesia mencapai US\$ 8 miliar dolar (Tempo.co, 2018). Pada harbolnas tahun 2017, Insight Nielsen Indonesia mencatat total transaksi yang terjadi sebesar 4,7 
triliun rupiah, angka ini meningkat sebesar 1,4 triliun rupiah dibandingkan transaksi pada tahun 2016 (Detikinet, 2017). E-commerce sendiri menimbulkan perubahan perilaku pembelian konsumen menjadi impulse buying, yaitu melakukan pembelian yang tidak direncanakan (Natasya, 2016). Menurut Strens (1962) impulse buying adalah suatu pembelian yang dilakukan konsumen tanpa direncanakan sebelumnya.

Menurut Noorlaily, 2015, bagi pelanggan online, melakukan transaksi dengan penjual/start up secara online akan mempertimbangkan ketidakpastian dan resiko jika dibandingkan dengan transaksi jual beli secara tradisional. Pembeli diberikan kesempatan yang sedikit untuk mengetahui kualitas barang dan melakukan pengujian terhadap produk yang diinginkan melalui media Web yang disediakan oleh penjual. Ketika pelanggan melakukan pembelian dari website penjual yang tidak dikenal, pelanggan tidak dapat mengetahui kualitas barang dan jasa yang di tawarkan apakah masuk akal dan dapat diandalkan atau tidak.

Dari uraian di atas, maka peneliti tertarik untuk melihat "Faktor yang mempengaruhi impulse buying konsumen yang berbelanja pada moment hari belanja nasional (harbolnas)". Berdasarkan rumusan masalah di atas, maka tujuan khusus yang ingin dicapai dalam penelitian ini adalah :

1. Menganalisis Faktor yang mempengaruhi impulse buying konsumen yang berbelanja pada moment harbolnas.

2. Menganalisis faktor yang dominan mempengaruhi impulse buying pada moment harbolnas.

\section{TINJAUAN PUSTAKA}

Perkembangan bisnis secara online yang mampu menggeser bisnis konvensional menjadi ketertarikan utama peneliti, di tambah dengan diluncurkannya program hari belanja online (HARBOLNAS) oleh idEA yang tujuannya tidak lain untuk lebih meningkatkan minat konsumen berbelanja secara online. Beberapa penelitian menunjukan bahwa berbelanja secara online ditambah dengan promo besar-besaran menimbulkan impulse buying kepada konsumen.

Impulse buying merupakan pembelian yang tidak direncanakan dan pembelian terencana dari seorang konsumen, dimana keputusan pembelian konsumen tidak dengan melakukan evaluasi produk ((Vohs \& Faber 2003; Parboteeah 2005). Beberapa faktor yang mempengaruhi konsumen melakukan impulse buying antara lain promosi, lingkungan toko, windows display, tampilan barang dagangan, tingkat pendapatan dan kartu kredit (Vishnu., et al, 2013). Dan hasil yang diperoleh adalah tingkat pendapatan dan tampilan barang dagangan memberikan faktor yang paling besar terhadap impulse buying. Menurut Akram, et.al, 2018, impulse buying dipengaruhi oleh Scarcity, serendipity information, social shopping, adventure shopping, value shopping, relaxation shopping dan idea shooping, dimana faktor yang paling dominan mempengaruhi impulse buying adalah serendipity dengan $\mathrm{R}^{2}$ sebesar 0,490 atau $49 \%$.

Emosi konsumen berpengaruh positif terhadap impulse buying (Shahnaz, 2014). Ketersediaan uang memberikan pengaruh positif terhadap impulse buying (Jung Hyo, 2014). Kartu kredit juga menambah keinginan konsumen untuk melakukan impulse buying (Alireza, 2011). Emosi dan hasrat dalam diri konsumen meningkatkan keinginan untuk melakukan impulse buying (Grace, 2008; Alireza, 2011 dan Shahnaz, 2014). Menurut Damayanti, 2015, perilaku impulse buying konsumen pada online dan in-store dapat dilihat dari environment, promotion, payment, product, dan availability. 
Belanja Impulsif dikelompokkan ke dalam empat tipe (Stern, 1962 dalam Soeseno Bong, 2011). Pertama, Pure Impulse Buying, yaitu perilaku belanja im- pulsif murni yang tidak membuat perencanaan sebelum keputusan pembelian diambil, dan ini diasumsikan sebagai perilaku belanja menyimpang dari perilaku belanja normatif. Kedua, Reminder Impulse Buying, adalah perilaku belanja yang dipacu oleh faktor pengingat seperti misalnya calon konsumen teringat bahwa cadangan di rumah sudah menipis pada waktu kebetulan konsumen melihat tawaran produk-produk tersebut di toko. Ketiga, Suggestion Impulse Buying, adalah perilaku belanja terpacu oleh adanya program promosi di dalam toko atau konsumen menemukan visualisasi promosi menarik di toko walau pun belum terlalu mengenal produk yang dipromosikan tersebut, namun terpen- garuh membeli karena usulan program promosi tersebut. Keempat, Planned Impulse Buying, adalah perilaku belanja bahwa keputusan pembelian berdasarkan perencanaan walaupun aksi pembelian itu sendiri tidak sesuai dengan rencana, sebab konsumen di pacu oleh kampanye promosi atau penawaran khusus, sebagai contoh program potongan harga, fitur produk baru dari produk sejenis atau produk-produk substitusi.

Menurut penelitian Engel (1995), pembelian berdasar impulse mungkin memiliki satu atau lebih karakteristik ini :

1. Spontanitas. Pembelian ini tidak diharapkan dan išpememotivasi konsumen untuk membeli sekarang, sering sebagai respons terhadap stimulasi visual yang langsung di tempat penjualan.

2. Kekuatan, kompulsi, dan intensitas. Mungkin ada motivasi untuk mengesampingkan semua yang lain dan bertindak dengan seketika.

3. Kegairahan dan stimulasi. Desakan mendadak untuk membeli sering disertai dengan emosi yang dicirikan sebagai "menggairahkan", "menggetarkan," atau " liar."

4. Ketidakpedulian akan akibat. Desakan untuk membeli dapat menjadi begitu sulit ditolak sehingga akibat yang mungkin negatif diabaikan.

Penelitian terdahulu yang telah dilakukan lebih kepada belanja online secara umum, sedangkan dalam penelitian ini, peneliti tertarik untuk melihat lebih khusus bagaimana konsumen berperilaku terutama perilaku impulse buying di saat moment Hari Belanja Online (Harbolnas) dengan faktor-faktor yang mempengaruhi impulse buying yang dikemukakan oleh Damayanti, 2015 yaitu Environment, Promosi, Tingkat Pendapatan, Metode Pembayaran, Ketersediaan Produk, Emosi dan Serrendipity.

\section{METODE PENELITIAN}

Penelitian ini merupakan jenis penelitian deskriptif verifikatif, dari penelitian ini juga diharapkan memperoleh gambaran mengenai variable impulse buying konsumen saat moment HARBOLNAS (Hari Belanja Online). Instrument atau alat yang digunakan dalam menghimpun kuisioner yaitu data dalam bentuk kuisioner berupa pernyataan. Untuk menentukan nilai atau skor kuisioner dengan menggunakan skala likert, yaitu untuk mengubah data-data kualitatif yang diperoleh menjadi data kuantitatif. Skala likert merupakan metode yang digunakan untuk mengukur sikap (Sugiono ; 2008).

Ukuran yang digunakan untuk menilai jawaban-jawaban yang diberikan terdapat empat (4) tingkatan yaitu 1 untuk jawaban sangat tidak setuju, 2 untuk jawaban tidak setuju, 3 untuk jawaban setuju 4 untuk jawaban sangat setuju. Kemudian hasil tabulasinya di olah dengan rata-rata dan cross tabulation. Cross tabulation digunakan untuk menampilkan tabulasi silang ) yang menunjukan suatu distribusi bersama terhadap dua variable atau lebih, yang dalam penelitian ini untuk melihat kecenderungan dari identitas 
responden (Jenis kelamin, usia, pendapatan, pendidikan dan pekerjaan) terhadap variablevariabel yang mempengaruhi impulse buying. Alat bantunya dengan SPSS 19.

Adapun rentang skor dalam penelitian ini berdasarkan pendapat Sudjana (1990) yang didasarkan pada penggunaan skala Likert, yaitu sebagai berikut :

$1,00-1,99:$ : termasuk kategori negatif (sangat tidak setuju/sangat tidak berpengaruh)

$2,00-2,99:$ kategori negatif (tidak setuju/tidak berpengaruh)

$3,00-3,99:$ kategori positif (setuju/berpengaruh)

$4,00-4,99:$ kategori positif (sangat setuju/sangat berpengaruh)

\section{HASIL DAN PEMBAHASAN}

Variabel yang di analisis dalam penelitian ini menjelaskan factor-faktor yang mempengrauhi Impulse Buying yang terdiri atas Environment (lingkungan), Promosi, Metode Pembayaran, Produk, Emosi dan Serrendipity. Hasil tanggapan responden atas variable-variabel tersebut dapat dijelaskan sebagai berikut :

Tabel 1. Tanggapan Responden atas Variable Impulse Buying

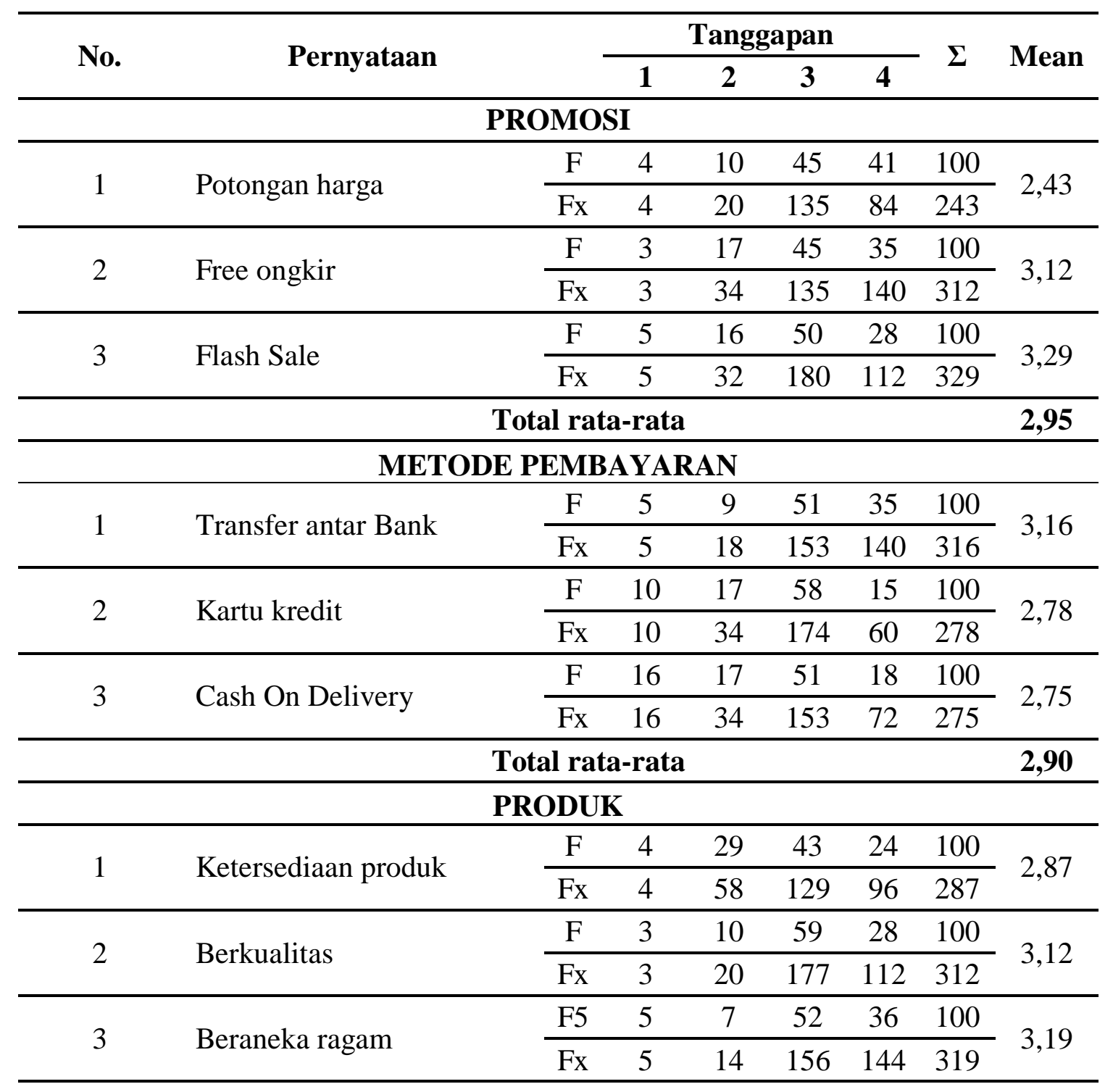


Jurnal Manajemen Terapan dan Keuangan (Mankeu) Vol. 10 No. 01, April 2021 P-ISSN: 2252-8636, E-ISSN: 2685-9424

\begin{tabular}{|c|c|c|c|c|c|c|c|c|}
\hline \multirow{2}{*}{ No. } & \multirow{2}{*}{ Pernyataan } & & \multicolumn{4}{|c|}{ Tanggapan } & \multirow{2}{*}{$\Sigma$} & \multirow{2}{*}{ Mean } \\
\hline & & & 1 & 2 & 3 & 4 & & \\
\hline \multirow{2}{*}{4} & \multirow{2}{*}{ Harga terjangkau } & $\mathrm{F}$ & 5 & 12 & 48 & 31 & 100 & \multirow{2}{*}{2,97} \\
\hline & & Fx & 5 & 24 & 144 & 124 & 297 & \\
\hline \multirow{2}{*}{5} & \multirow{2}{*}{ Merek sudah dikenal } & $\mathrm{F}$ & 6 & 11 & 45 & 38 & 100 & \multirow{2}{*}{3,15} \\
\hline & & Fx & 6 & 22 & 135 & 152 & 315 & \\
\hline \multicolumn{8}{|c|}{ Total rata-rata } & 3,06 \\
\hline \multicolumn{9}{|c|}{ EMOSI } \\
\hline \multirow{2}{*}{1} & \multirow{2}{*}{ Pemenuhan Kebutuhan } & $\mathrm{F}$ & 7 & 14 & 47 & 32 & 100 & \multirow{2}{*}{3,04} \\
\hline & & Fx & 7 & 28 & 141 & 128 & 304 & \\
\hline \multirow{2}{*}{2} & \multirow{2}{*}{ Menunjukan jati diri } & $\mathrm{F}$ & 9 & 30 & 38 & 34 & 100 & \multirow{2}{*}{3,19} \\
\hline & & Fx & 9 & 60 & 114 & 136 & 319 & \\
\hline \multirow{2}{*}{3} & \multirow{2}{*}{ Tuntutan gaya hidup } & $\mathrm{F}$ & 12 & 13 & 48 & 27 & 100 & \multirow{2}{*}{3,00} \\
\hline & & Fx & 12 & 36 & 144 & 108 & 300 & \\
\hline \multicolumn{8}{|c|}{ Total rata-rata } & 3,08 \\
\hline \multicolumn{9}{|c|}{ SERENDIPITY } \\
\hline \multirow{2}{*}{1} & \multirow{2}{*}{$\begin{array}{l}\text { Mempunyai pengalaman } \\
\text { positif dengan belanja } \\
\text { online }\end{array}$} & $\mathrm{F}$ & 4 & 12 & 60 & 24 & 100 & \multirow{2}{*}{3,04} \\
\hline & & Fx & 4 & 24 & 180 & 96 & 304 & \\
\hline \multirow{2}{*}{2} & \multirow{2}{*}{ Berbelanja untuk relaksasi } & $\mathrm{F}$ & 13 & 27 & 49 & 11 & 100 & \multirow{2}{*}{2,58} \\
\hline & & Fx & 13 & 54 & 147 & 44 & 258 & \\
\hline \multirow{2}{*}{3} & \multirow{2}{*}{$\begin{array}{l}\text { Kemudahan dalam mencari } \\
\text { produk }\end{array}$} & $\mathrm{F}$ & 2 & 11 & 66 & 21 & 100 & \multirow{2}{*}{3,06} \\
\hline & & Fx & 2 & 22 & 198 & 84 & 306 & \\
\hline
\end{tabular}

Sumber : Hasil olahan data, 2019.

Dari tabel di atas terlihat bahwa variable emosi memiliki rata-rata tertinggi yaitu sebesar 3,08 dengan kategori positif. Hal ini sesuai dengan penelitian yang dilakukan oleh Grace, 2008; Alireza, 2011, Shahnaz 2014. Artinya moment harbolnas memunculkan keinginan untuk menunjukan jati diri dan memenuhi gaya hidup konsumen, sedangkan variable serendipity memberikan rata-rata terendah yaitu sebesar 2,89 dengan kategori negative. Serendipity di sini menunjukan bahwa ketertarikan konsumen untuk berbelanja secara online pada moment harbolnas karena adanya pengalaman sebelumnya, dan karena berbelanja menimbulkan rekasasi serta kemudahan dalam mencari produk.

Alat analisis yang kedua yang digunakan adalah Cross Tabulation, yaitu dengan membandingkan identitas responden dengan variable yang digunakan dalam penelitian. Cross tabulation pertama dilakukan antara Jenis kelamin responden dengan variable Environment, variabel Promosi, metode pembayaran, variable produk, emosi dan serendipity. Hasil diperoleh sebagai berikut bahwa dari jenis kelamin responden diperoleh informasi dari total pria berjumlah 43 maka sebanyak 31 orang tertarik untuk berbelanja 
pada moment harbolnas karena mendapatkan kemudahan dalam mencari produk yang merupakan indikator dari variable serendipity. sedangkan dari total 57 wanita, sebanyak 36 orang lebih memilih virtual atmosphere atau suasana/situasi belanja saat moment harbolnas. Dari sisi usia mayoritas responden berada pada rentang usia 15 - 20 tahun yaitu sebanyak 39 orang. Impulse buying pada kategori usia 15 - 20 tahun timbul karena kegiatan berbelanja merupakan salah satu bentuk penyegaran (relaxation) dari rutinitas yang mereka jalani sehari-hari. Dan jika dilihat dari sisi pendidikan mayoritas adalah lulusan SMU sederajat.

Dari sisi pekerjaan mayoritas merupakan wirausaha yaitu sebanyak 52 orang. Responden yang memiliki pekerjaan sebagai wirausaha tertarik melakukan impulse buying pada moment harbolnas dikarenakan situasi atau suasana yang timbul pada saat itu. Diketahui bahwa harbolnas dilakukan di akhir tahun atau dikenal dengan 12.12 (tanggal 12 bulan 12). Pada moment ini hampir seluruh penjual online melakukan promosi besarbesaran baik itu dengan memberikan potongan harga maupun dengan promosi penjualan seperti beli 1 produk gratis 1 .

\section{SIMPULAN DAN SARAN}

\section{Simpulan}

1. Impulse buying konsumen saat momen harbolnas timbul dikarenakan adanya faktor emosi yang terdiri atas indikator keinginan untuk menunjukkan jati diri dan memenuhi gaya hidup.

2. Dari cross tabulation diperoleh informasi bahwa mayoritas konsumen adalah wanita, dengan rentang usia antara 15 - 20 tahun yang berpendidikan minimal SMU sederajat dan memiliki pekerjaan sebagai wirausaha.

\section{Saran}

Para pelaku bisnis online dapat memperhatikan target pasar yang paling banyak adalah remaja yang membutuhkan pembuktian diri dan memenuhi gaya hidupnya.

Perlunya dukungan pemerintah baik pusat maupun daerah kepada pelaku usaha bisnis online untuk terus melakukan kegiatan-kegiatan yang dapat menstimuli konsumen berbelanja secara online.

\section{DAFTAR PUSTAKA}

Agus Tri Haryanto. 2019. Pengguna Internet Indonesia Didominasi Milenial. Inet.detik.com.

Akram, Umair, Peng Hui, Muhammad Kaleem Khan, Chen Yan \& Zubair Akram. 2018. Factor Affecting Online Impulse Buying : Evidence from Chinese Social Commerce Environment. Journal Sustainability. www.mdpi.com/journal/sustainability.

Alireza, Karbasivar, Yarahmadi Hasti. 2011. Evaluating Effective Factors on Consumer Impulse Buying Behavior. Asian Journal of Business Management Studies, pp.174181.

Chang Jung Hyo, Yan Rouh-Nan, Eckman Molly. 2014. Moderating Effects of Situational Characteristics on Impulse Buying. International Journal of Retail \& Distribution anagement Vo.2 No.4, pp. 298-314.

Damayanti Octavia, 2016. The Differences of Online and In-store Impulse Buying Behaviour using Stimulus and Response Model. ISCLO. Atlantis Press.

Engel, James F., Blackwell, R.D. \& Miniard, P.W., 1995, Perilaku konsumen, Jilid 1 (Edisi ke- enam), Jakarta: Binarupa Aksara. 
Grace, Lee Yuna, Yi Youjae. 2008. The Effect of Shopping Emotions and Perceived Risk on Impulse Buying: The Moderating Role of Buying Impulsiveness Trait. Seoul Journal of Business, Vol.14 No.2, pp. 67-92 .

Japarianto, E. and Sugiharto, S. 2011. Pengaruh shopping life style dan fashion involvement terhadap impulse buying behavior masyarakat high income surabaya . Jurnal Manajemen Pemasaran, Vol. 6, No. 1, pp.32-41

Noorlaily Fithdiarini. 2015. Kepercayaan Pelanggan Untuk Melakukan Online Shopping dan Dampaknya Terhadap Minat Beli. Jurnal Ekonomi dan Bisnis. Tahun XXVI. No. 3. Hal. 256-269.

Parboteeah, D. V., 2005. A model of online impulse buying: An empirical study. Doctoral dissertation Washington state university.

Shahnaz, Nayebzadeh, Jalaly Maryam. 2014. Investigating Iranian Female Muslim Consumer Impulse Buying Behaviour Used as a Form of Retail Therapy. Journal of Islamic Marketing Vo.5 No.2, pp. 302-320.

Soeseno Bong. 2011. Pengaruh In-store Stimuli Terhadap Impulse Buying Behaviour Konsumen Hypermarket di Jakarta. Ultima Management. Vol. 3. No.1. hal. 31-52.

Tempo.co. 2017. Ini Hasil Riset Google Soal Perilaku Belanja Onlie di Indonesia. Selasa, 15 Agustus 2017.

Vishnu, Parmar \& Ahmeed Rizwan Raheem. 2013. European Journal of Scientific Research. Vol. 100. No.3. pp. 67-79.

Vohs, K., and Ronald Faber, R., 2003."Self-Regulation and Impulsive Spending Patterns", in NA-Advances in Consumer Research Volume 30, Eds. Pp: 125-126 